\title{
Proceeding
}

Supplementary Issue: Autumn Conferences of Sports Science. Costa Blanca Sports Science Events, 2-3 November 2018.

Alicante, Spain

\section{Recreational physical activity participation among women in Saudi Arabia}

\author{
BADR A. FALLATAH ${ }^{1} \triangleleft$, HONG SEOK PYO ${ }^{1}$, BASIM N. ALSALEH ${ }^{2}$ \\ ${ }^{1}$ Division of Sport Science, Kangwon National University, Saudi Arabia \\ 2Physical Education Department, Umm Alqura University, Saudi Arabia
}

\begin{abstract}
Background. Despite that Kingdom of Saudi Arabia places emphasizes on importance of protecting female population, with the absence of physical education for girls in schools that only ceased till very recently, limited number of fitness centres and gyms for women, a particular body image and prevalence of women staying at home and having rather passive or static life have created a somewhat unhealthy lifestyle among women. Methods. Participating women (161; ages 17-44), from Saudi Arabia, completed the survey that assessing fitness environment in the physical centre which are layout, aesthetics and personnel as well the intangible like social interaction and gym experience can be positively influence attendees' motivation and increase the numbers of the fitness clubs. Therefore, motivation factors could have positive influence on willingness to come back to the gym among females. Results. SPSS showed tangible attributes of the fitness were not significant while social factors were significantly affected motivation to attend the female centres $(p<0.001)$. On the other hand, the influence of motivation is showing to be significant in willingness to come back to the centre $(p<0.001)$. Key words: Women in Saudi Arabia; Fitness centre; Social; Motivation; Saudi Arabia.
\end{abstract}

\section{Cite this article as:}

Fallatah, B.A., Seok-Pyo, H., \& Alsaleh, B.N. (2019). Recreational physical activity participation among women in Saudi Arabia. Journal of Human Sport and Exercise, 14(1proc), S84-S91. doi:https://doi.org/10.14198//hse.2019.14.Proc1.10

Corresponding author. Division of Sport Science, Kangwon National University, Saudi Arabia.

E-mail: badrfallatah@gmail.com

Supplementary Issue: Autumn Conferences of Sports Science. Costa Blanca Sports Science Events, 2-3 November 2018. Alicante, Spain.

JOURNAL OF HUMAN SPORT \& EXERCISE ISSN 1988-5202

(c) Faculty of Education. University of Alicante.

doi:10.14198/jhse.2019.14.Proc1.10 


\section{INTRODUCTION}

Medical studies reveal that $70 \%$ of the general adult population of Saudi Arabia suffers from obesity and consequently- by caring excess weight. Among this $70 \%$, more than half regards women (37\%), and number of females facing problems related to the overweight is progressing in its numbers. Moreover, limited number of fitness centres and gyms, undeveloped fitness environment for women, and luck of its popularity creates a problematic situation that can potentially cause a lot of health and financial problems. Thus we strive to investigate what are the factors that are influential to the participation of women in recreational physical activities and how it can be increased. Thus, we investigate fitness environment in its physical and social aspects, and personal motivation factors and see how they influence willingness to participate and attend recreational physical activities. In this section of the study related literature that contributed to the establishment of the proposed research model (Figure 1) is discussed below. Physical attributes of the fitness centre which are reflected by fitness centre layout, fitness centre aesthetics and personnel in this study, have been emphasized by scholars as critical elements that create pleasant fitness centre atmosphere which it has been emphasized in the paper of Balaji and Chakraborti (2015) as critical factors that constitute the atmosphere for the sports facility. Moreover, such physical aspects can attract fitness work out participant with an attractive setting, convenient layout, ease of accessibility and etc. In such instance, sports marketing research emphasizes that physical environment of consumption is greatly influential to customers' perception and behaviour that can potentially predict satisfaction and attendance decisions (Greenwell et al. 2002; Joseph-Mathews et al., 2009). Thus, we hypothesize that:

H1: Fitness centre tangible attributes reflected through layout, aesthetics and personnel positively influence attendee's motivation to work out.

Although fitness centre by itself represents a physical environment that is easily grasped due to its tangible attributes such as layout and aesthetics, there are social attributes that are although intangible, but greatly tied to the facility, as it accommodates it. Besides, such attributes like social interaction and fitness experience have been empirically emphasized to be critical in establishing stadium atmosphere along with physical element of facility layout and interior (Balaji \& Chakrabortu, 2015). Several scholars emphasized entertainment and experience are significant factors when evaluating key factors that influence spectators' willingness to come back to watch National Basketball Association (NBA) matches Zhang et al. (2003). In his research on evaluating motivational factors McDonald et al. (2002) discussed social gratification that is associated with those that experience and enjoy same activity as the key motivational determinant for Participants in similar sports.

Moreover, Mueller \& Reznik (1979) noted how participation in free sport can linking with the individual's personal needs such as self-expression, self-reliance, self-esteem and the need to belong. Indeed, benefits from sport can be linked to the positive experiences such as new challenges, social interactions and increased levels of fitness in enhancing perceived social acceptance. Thus, fitness centres or gyms might well be interpreted as a connecting place that takes on the social facilitation role, which might potentially increase attendance rate of the fitness clubs and motivate customers (Won \& Kitamura, 2006; Zhang et al. 2004).; hence we hypothesize:

H2: Fitness centre social attributes reflected through fitness experience and social interaction positively influences attendees' motivation to work out. 
In the same manner, motivation to work has been acknowledged to be one of the key factors influencing willingness to come back to the gym. In a similar way, numerous studies have emphasized social interaction between spectators as a prerequisite for spectators to make a decision on whether to attend next event at the particular stadium or not. For instance, in the work by Won and Kitamura (2006) that concerned motivational factors that are influential to the spectators' retention at the sport venues social interaction was found to be significant in determining and predicting spectators' attendance within Japan league context. Furthermore, scholars emphasize that motivation is established through socio-psychological element that influence the decision making (Sirakaya and Woodside, 2005). For instance, in the case of the motivation to come back to fitness clubs can be influence by social factors such as appearance, stress management, competition, challenge and buffer against anxiety (Dimech and Seiler, 2011). Besides, positive health like obesity, hypertension and other motives related to affiliation, challenge, friendships and gym service delivery are other reasons people continued to attend sport centres (Hirsch, 2005).

H3: Motivation to work out in the fitness club has positive influence on willingness to come back to the gym among females.

This section discusses the relevant literature that contributed to the establishment of the proposed research model (Figure 1).

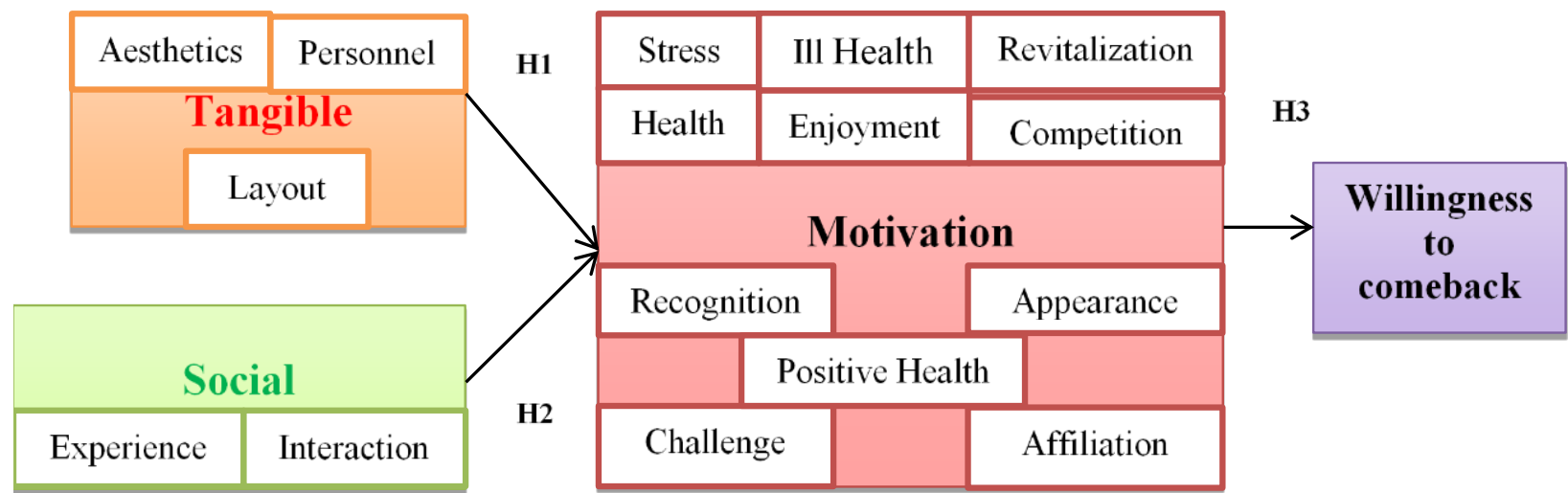

Figure 1. Proposed research model - Motivational Factors

\section{METHODS AND MATERIALS}

\section{Participants}

In this study, the sample was composed of 190 samples who completed the mixed survey methodology that measuring all the 67 items, were directly distributed and sent via email by research assistant to female members of the fitness centres and gyms in Saudi Arabia in the cities of Jeddah within 3 weeks period from October 9th to October 28th, 2017 and response rate resulted to be 85\% (131) from overall size of samples.

\section{Evaluation instrument}

To conduct this research, we utilized the survey method as it is the best suited to describe and enumerate objects, beliefs, and perceptions, as well as establishing/proving claims about their characteristics (Diamond, 2000). 
To be precise, we applied a mixed survey methodology that primarily consisted of directly administered surveys and web-based surveys carried out through platforms such as Google Forms, for in terms of time and cost consideration they are considered to be the most appropriate and most effective in terms of higher response rate and higher response objectivity (Wilkinson and McNeil, 1996). Prior to the primary survey, all items were reviewed by three academic professors who evaluated the appropriateness of the research constructs and related items. Based on their feedback, vague and redundant items were either eliminated or modified. Then, the final versions of both survey questionnaires' types, measuring all the 37 items, were directly distributed and sent via email by research assistant to female members of the fitness centres and gyms in Saudi Arabia in the cities of Jeddah.

\section{Procedure}

Questionnaires were distributed within a 3-week period from January 9th to January 28th, 2018, and the response rate was $85 \%$ (161) from an overall size of 190 samples. After screening all data sets for incorrectly filled or incomplete questionnaires overall size was reduced to 131 complete questionnaires. Furthermore, all constructs of fitness centre tangible and social attributes and motivation were modelled as second-order super-ordinate constructs (Chin 1998; Edwards 2001). Each of the constituent dimensions to second-order constructs were measured reflectively and in turn reflected them. Such modelling decision was due to all dimensions of second-order constructs are interdependent and unlikely to exist independently of one another. For instance, when respondents assess facility aesthetics they most likely be impacted by their evaluation of fitness centre layout primarily because such physical attributes are contributed to the overall appearance and convenience of the facility and to a certain degree represent tangible elements of the stadium that are critical to the visitors' convenience.

In the same manner, evaluations of fitness experience are associated with the evaluations of the social interaction as they also critical to the establishment of the pleasant game atmosphere. Furthermore, while visitors evaluate their attachment to the facility such factors like motivation to either come back to fitness centre. Moreover, natural sampling method was used due to the little influence on the composition of the sample respondents (Hussey and Hussey, 1997). All items used for the construct were adapted from validated instruments modified in order to fit sport's marketing context. In order to ensure statistical variability seven-point Likert scale was used from "strongly agree" to "strongly disagree" to rate each item.

\section{Data analysis}

Prior to conducting the data analysis, all datasets were screened to indicate outliers, and to expose and exclude extreme datasets through SPSS 22 in order to improve performance of the statistical methods (Odom \& Henson, 2002). Then, our proposed research model was tested in SmartPLS 2.0 software, which is a form of structural equation modelling (SEM), appropriate for multi-variate model analysis (Chin, 1998).

\section{RESULTS}

In table 1, common method bias is not a threat to this study. Moreover, all reflective indicators showed good internal consistency and good discriminant validity, as square roots of AVE for each construct are greater than their correlations with other constructs (Table 2). Consequently, our proposed research model was tested in SmartPLS 2.0 software, which is a form of structural equation modelling (SEM) appropriate for multi-variate model's analysis (Chin, 1998). Results of the SEM analysis are discussed in the section below. 
Table 1. Cronbach's Alfa, Composite Reliability, AVE

\begin{tabular}{|c|c|c|c|}
\hline & $\begin{array}{r}\text { Cronbach's } \\
\text { Alpha }\end{array}$ & $\begin{array}{c}\text { Composite } \\
\text { Reliability }\end{array}$ & AVE \\
\hline Layout & 0.93 & 0.95 & 0.82 \\
\hline Aesthetics & 0.93 & 0.95 & 0.83 \\
\hline Personnel & 0.97 & 0.98 & 0.88 \\
\hline Experience & 0.96 & 0.98 & 0.93 \\
\hline Interaction & 0.92 & 0.95 & 0.87 \\
\hline Stress & 0.98 & 0.98 & 0.93 \\
\hline Recognition & 0.96 & 0.97 & 0.9 \\
\hline Revitalization & 0.91 & 0.94 & 0.78 \\
\hline Positive & 0.98 & 0.99 & 0.94 \\
health & & & 0.94 \\
\hline Ill health & 0.98 & 0.99 & \\
\hline
\end{tabular}

Table 2. Discriminant Validity

\begin{tabular}{|c|c|c|c|c|c|c|c|c|c|c|c|c|c|c|c|c|c|}
\hline & $\mathbf{1}$ & $\mathbf{2}$ & $\mathbf{3}$ & $\mathbf{4}$ & $\mathbf{5}$ & $\mathbf{6}$ & $\mathbf{7}$ & $\mathbf{8}$ & $\mathbf{9}$ & $\mathbf{1 0}$ & $\mathbf{1 1}$ & $\mathbf{1 2}$ & $\mathbf{1 3}$ & $\mathbf{1 4}$ & $\mathbf{1 5}$ & $\mathbf{1 6}$ & $\mathbf{1 7}$ \\
\hline 1 & 0.87 & & & & & & & & & & & & & & & & \\
\hline 2 & 0.48 & 0.96 & & & & & & & & & & & & & & & \\
\hline 3 & 0.61 & 0.51 & 0.91 & & & & & & & & & & & & & & \\
\hline 4 & 0.49 & 0.89 & 0.52 & 0.95 & & & & & & & & & & & & & \\
\hline 5 & 0.52 & 0.83 & 0.55 & 0.89 & 0.94 & & & & & & & & & & & & \\
\hline 6 & 0.58 & 0.46 & 0.55 & 0.48 & 0.58 & 0.94 & & & & & & & & & & & \\
\hline 7 & 0.54 & 0.73 & 0.46 & 0.6 & 0.59 & 0.46 & 0.83 & & & & & & & & & & \\
\hline 8 & 0.51 & 0.79 & 0.68 & 0.84 & 0.77 & 0.48 & 0.52 & 0.96 & & & & & & & & & \\
\hline 9 & 0.46 & 0.95 & 0.5 & 0.94 & 0.87 & 0.48 & 0.65 & 0.85 & 0.97 & & & & & & & & \\
\hline 10 & 0.66 & 0.68 & 0.62 & 0.74 & 0.66 & 0.54 & 0.54 & 0.82 & 0.71 & 0.93 & & & & & & & \\
\hline 11 & 0.61 & 0.66 & 0.87 & 0.69 & 0.68 & 0.52 & 0.53 & 0.77 & 0.68 & 0.69 & 0.91 & & & & & & \\
\hline 12 & 0.58 & 0.54 & 0.85 & 0.56 & 0.55 & 0.53 & 0.47 & 0.69 & 0.54 & 0.62 & 0.81 & 0.94 & & & & & \\
\hline 13 & 0.47 & 0.9 & 0.55 & 0.91 & 0.87 & 0.53 & 0.62 & 0.84 & 0.95 & 0.73 & 0.72 & 0.55 & 0.97 & & & & \\
\hline 14 & 0.73 & 0.54 & 0.58 & 0.52 & 0.58 & 0.67 & 0.6 & 0.5 & 0.54 & 0.58 & 0.54 & 0.58 & 0.5 & 0.89 & & & \\
\hline 15 & 0.53 & 0.77 & 0.6 & 0.77 & 0.82 & 0.64 & 0.68 & 0.76 & 0.8 & 0.65 & 0.68 & 0.57 & 0.85 & 0.64 & 0.95 & & \\
\hline 16 & 0.44 & 0.87 & 0.45 & 0.89 & 0.77 & 0.43 & 0.68 & 0.78 & 0.89 & 0.69 & 0.62 & 0.49 & 0.89 & 0.47 & 0.75 & 0.97 & \\
\hline 17 & 0.57 & 0.76 & 0.57 & 0.8 & 0.75 & 0.55 & 0.6 & 0.83 & 0.8 & 0.75 & 0.71 & 0.62 & 0.82 & 0.54 & 0.77 & 0.8 & 0.96 \\
\hline
\end{tabular}

Note: 1 - Affiliation, 2- Health, 3 -Aesthetics, 4 - Appearance, 5 - Challenge, 6 - Competiti on, 7 - Enjoyment, 8 - Experience, 9 - Ill Health, 10 - Interaction, 11 - Layout, 12 - Personne 1, 13 - Positive Health, 14 - Revitalization, 15 - Recognition, 16 - Stress, 17 - Willingness to comeback. 


\section{RESULTS}

Primary results of the structural equation modelling are illustrated in the Figure 2 and show values of constructs' $R$ squares and t-statistics, which are determinants of whether hypothesized relations are statistically significant. Critical values for two-tailed test are as in accordance with the work of Hair et al., (2011) where 1.65 indicates significance level of $10 \%, 1.96$ shows significance level of $5 \%$, and 2.58 indicates significance level of $1 \%$. Results of the SEM analysis are as follows. Tangible attributes of the fitness centre were not significant. On the other hand, social attributes $(\beta=0.75 p<0.001 ; t=7.22)$ significantly affected motivation to attend fitness centre among females, which supported $\mathrm{H} 2$. Thus, it confirms that social attributes of the venue influence motivation for females to work out. Furthermore, influence of the motivation is statistically proved to be significant in determining willingness to come back to the fitness centre. Thus, proving $\mathrm{H} 3$ ( $\beta=0.85 p<0.001 ; t=24.13$ ), which resulted to be the strongest relationships among others.

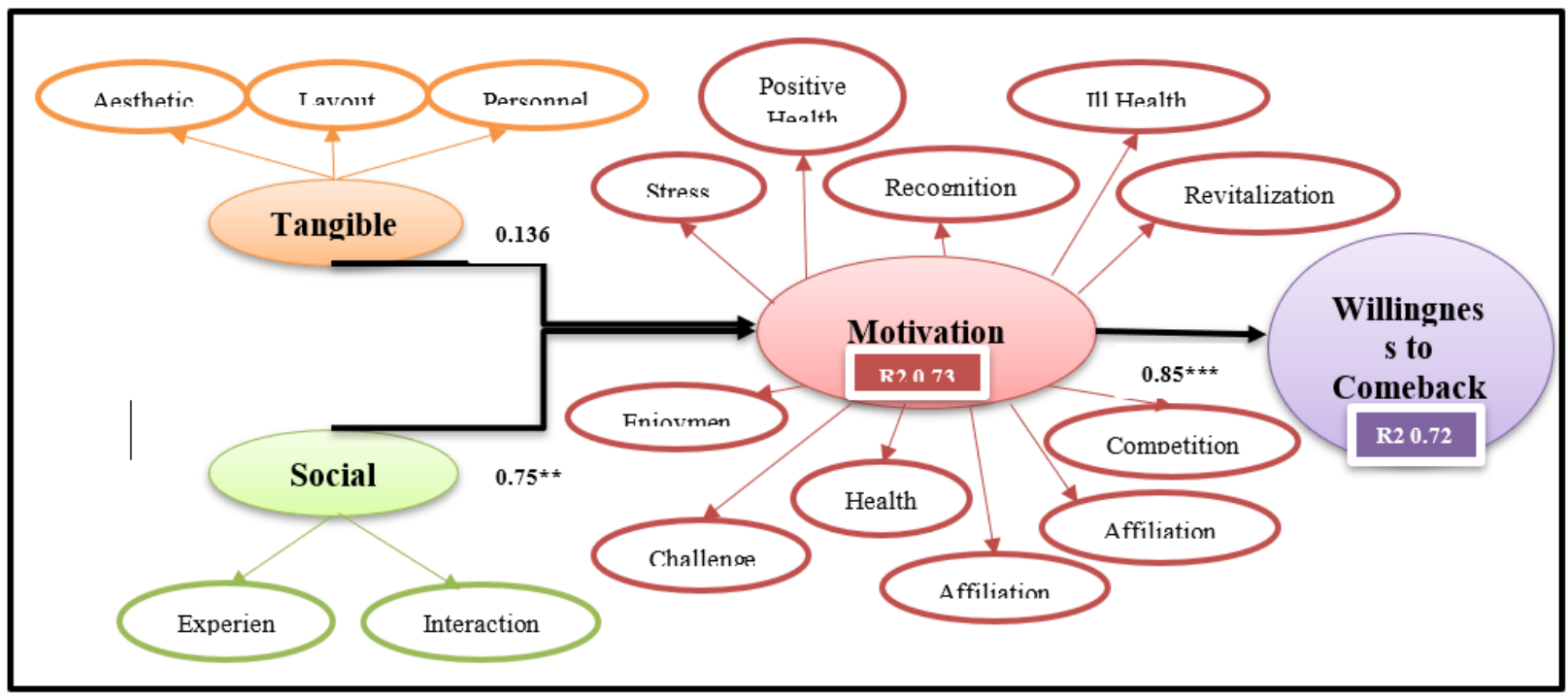

Figure 2. Results of the proposed research model

\begin{tabular}{|c|c|c|c|}
\hline & & T Statistics (|O/STDEV $\mid$ & Hypotheses \\
\hline H1 & Tangibles -> Motivation & 1.47 & Not significant \\
\hline $\mathbf{H 2}$ & Social -> Motivation & 7.22 & Significant \\
\hline H3 & Motivation -> Willingness to comeback & 24.13 & Significant \\
\hline
\end{tabular}

\section{DISCUSSION AND CONCLUSION}

Indeed, the history of health and diseases is long in both the east and west, Statistics showed that people who maintain a healthy lifestyle reduce the possibility of contracting chronic diseases such as headaches, blood pressure, and problems sleeping, obesity, heart disease, diabetes and depression. In Saudi Arabia, the major problem is not only growing health problem that predominantly affects female population, but rather passiveness in the work out behaviour. Furthermore, living a healthy life has become a key goal for many 
people because of its positive effects on their lives and routines. Health experts also recommend that people follow a healthy lifestyle, such as diet, fitness regime.

Unfortunately, many people have nutritional imbalance issues due to bad eating habits, lack of fitness activities and a lack of maintain health, it is necessary to have regular exercise and proper eating habit (Popkin et al., 2012). For example, these surveys (1990-93 and 1995-2000) reported that, all reports showed constantly higher obesity prevalence rates among women than men (45\%) in Saudi Arabian population. However, some of these challenges are difficult to address especially those that are associated with health and behaviour. Therefore, the key solution for these challenges is conducting research projects. Academics and expert doctors should carry out these research projects in order to find the best method to overcome them. Also, Saudi girls must be care about the importance of changing their lifestyle to reduce obesity and other diseases and increase their physical activity.

The benefits derived from sport cannot be denied. Not only physically but social benefits as well. However, the position of women in Islamic society in general and in Saudi Arabian society in particular is a complex. Saudi Arabia is the most restrictive countries in regard to women sports in the world. They face severe obstacles in many aspects of their lives including sport systems (Hamadah, 2006). Women are not allowed to sporting on public roads in large cities and religious police enforce a modest code of dress. They must wear the "Hijab" which is covering the limbs and the head. In recent years however, many people in the Kingdom have reported that women sport has become less strict. With a very limited number of females attending fitness centre due to the social and culture factors as well as the very practical ones, such as a very limited amount of fitness clubs in the country. Previous studies found the major reason is while many private sport clubs are seeking women staff, but it's difficult and costly. Also, female must be to train only with other women. In case of hard working woman, this study the roles highlights of how these female workers can attend women gyms. In Saudi Arabia, a married woman must also have the permission of her husband beforehand, and must ensure that none of her duties as a wife are being sacrificed as a result of her sport activities.

In summary, we tried to see what influences women to attend and/or comeback to the fitness centre. Surprisingly, tangible aspects we found to be not significant. In a country where fitness industry is not well developed, especially among women, which means that fitness club customers would not be aware of the quality of the facility in its practical sense. On the other hand, Successful layout is capable of providing ease of access to the specific points in fitness centres and adequate space. According to some of the scholars in sports marketing field physical layout factor is one of the key influential attributes that impacts perception and behavioural reactions of spectators. Also, fitness centre facility is a predicting factor to the spectators' satisfaction and decision to comeback. Whereas, many of local female players in gyms believed it is a very positive in the culture characteristics theme because they are closer to other players in term of personal and social relationships. As well as, discuss some problems that participants have and to create a friendship relationship. Another motivation is how feeling are when the perfect goal will be done in the end.

\section{REFERENCES}

Balaji, M. S., \& Chakraborti, R. (2015). Stadium atmosphere: Scale development and validation in an Indian context. Journal of Indian Business Research, 7(1), 45-66. https://doi.org/10.1108/JIBR-052014-0029

Chin, W. W. (1998). Issues and opinion on structural equation modelling. MIS Quarterly, 22(1), 7-16. 
Diamond, S. S. (2000). Reference guide on survey research. Reference Manual on Scientific Evidence, 225-271.

Gwinner, K., \& Swanson, S. (2003). A model of fan identification: Antecedents and sponsorship outcomes. Journal of Services Marketing, 17, 275-294. https://doi.org/10.1108/08876040310474828

Hair, J.F., Ringle, C.M., \& Sarstedt, M. (2011). PLS-SEM: Indeed a silver bullet. Journal of Marketing Theory and Practice ,19 (2), 139-151. https://doi.org/10.2753/MTP1069-6679190202

Harman, H. H. (1967). Modern Factor Analysis. Chicago: University of Chicago Press.

Hernandez - Lobato, L. et al. (2006). Tourism destination image, satisfaction and loyalty: A study in Ixtapa-Zihuatanejo, Mexico, Tourism geographies, V. 8, No. 4, 2006, pp.343-358.

Hussey, J., \& Hussey, R. (1997). Business research: A practical guide for undergraduate and postgraduate student. New York: Palgrave. https://doi.org/10.1007/978-1-349-25262-6

Larson, B.V., Jensen, R. and Bowman, N.D. (2011), "Developing international sports markets: Professional sports selling to new segments with new promotions", Journal of International Business Disciplines, Vol. 6 No. 2, pp. 9-24.

Lee, J., A. R. Graefe, and R. C. Burns. (2007). "Examining the Antecedents of Destination Loyalty in a Forest Setting." Leisure Studies, 29: 463-81. https://doi.org/10.1080/01490400701544634

Lee, J., Kyle, G., \& Scott, D. (2012). The mediating effect of place attachment on the relationship between festival satisfaction and loyalty to the festival hosting destination. Journal of Travel Research, 51(6), 754-767. https://doi.org/10.1177/0047287512437859

McDonald, H., Karg, A.J. and Lock, D. (2010). "Leveraging fans' global football allegiances to build domestic league support", Asia Pacific Journal of Marketing and Logistics, Vol. 22 No. 1, pp. 67-89. https://doi.org/10.1108/13555851011013164

Odom, L., \& Henson, R. (2002). Data screening: Essential techniques for data review and preparation. Paper presented at the Annual Meeting of the Southwest Educational Research Association.

Prayag, G. and Ryan C. (2011). Antecedents of tourists loyalty to Mauritius: The role and influence of destination image, place attachment, personal involvement and satisfaction, http://academia.edul, 2011, [accessed 05.01.2012].

Schriesheim, C. A. (1979). The similarity of individual directed and group directed leader behavior descriptions. Academy of Management Journal, 22(2), 345-355.

Tsiotsou, R. (2013). Sport team loyalty: Integrating relationship marketing and a hierarchy of effects. Journal of Services Marketing, 27(6), 458-471. https://doi.org/10.1108/JSM-01-2012-0002

Wilkinson, W. K., \& McNeil, K. A. (1996). Research for the helping professions. Brooks/Cole.

Yoshida, M., \& James, J. D. (2011). Service quality at sporting events: Is aesthetic quality a missing dimension? Sport Management Review, 14(1), 13-24. https://doi.org/10.1016/i.smr.2009.06.002

Yoshida, M., James, J. D., \& Cronin, J. J. (2013). Sport event innovativeness: Conceptualization, measurement, and its impact on consumer behavior. Sport Management Review, 16(1), 68-84. https://doi.org/10.1016/i.smr.2012.03.003

Yüksel, A., F. Yüksel, and Y. Bilim. (2010). "Destination Attachment: Effects on Customer Satisfaction and Cognitive, Affective and Conative Loyalty." Tourism Management, 31 (2): 274-84. https://doi.org/10.1016/j.tourman.2009.03.007

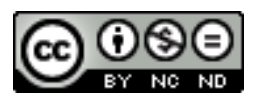

This work is licensed under a Attribution-NonCommercial-NoDerivatives 4.0 International (CC BY-NC-ND 4.0). 